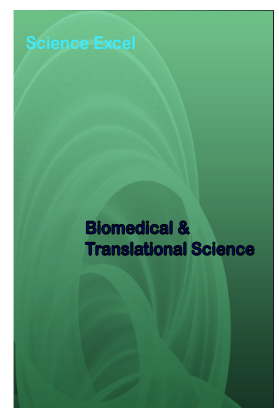

Correspondence

Alcántara Quintana L. E

Catedra CONACyT, Coordinación para la Innovación de la Aplicación de la Ciencia y Tecnología, Universidad Autónoma de San Luis Potosí. Av.Sierra Leona 5550, Lomas 2a sección, 78120, San Luis Potosí, México. E-mail: luz.alcantara@uaslp.mx lealcantara@conacyt.mx

- Received Date: 10 May 2021

- Accepted Date: 15 May 2021

- Publication Date: 18 May 2021

Copyright

(C) 2021 Science Excel. This is an openaccess article distributed under the terms of the Creative Commons Attribution 4.0 International license.

\title{
Severe SARS-CoV-2 infection: Mortality and comorbidities in a third level hospital in San Luis Potosi, Mexico
}

\author{
Garcia-Ruiz R' ${ }^{1}$, Benitez-Arvizu G' ${ }^{2}$, Salas-Rojas $\mathbf{M}^{3}$, Galvez-Romero $\mathbf{G}^{3}$, Flores- \\ Ramirez R$^{4}$, Diaz-Barriga F ${ }^{4}$, Perez-Vazquez $F^{4}$, Alcantara Quintana LE $^{4^{*}}$
}

${ }^{1}$ Facultad de Medicina, Universidad Naciona Autónoma de México. CDMX, México

${ }^{2}$ Banco de Sangre, Centro Médico Nacional Siglo XXI, Instituto Mexicano del Seguro Social, CDMX, México ${ }^{3}$ Unidad de Investigación Médica en Inmunología, UMAE Hospital de Pediatría, Centro Médico Nacional Siglo XXI, Instituto Mexicano del Seguro Social, CDMX, México

${ }^{4}$ Coordinación para la Innovación de la Aplicación de la Ciencia y Tecnología, Universidad Autónoma de San Luis Potosí, Mexico

\begin{abstract}
The high rates of hypertension, obesity and diabetes in San Luis Potosí are worrying, since it has been shown that the existence of comorbidities associated with SARS-CoV-2 infection increases the risk of mortality, however most of the evidence comes from of other populations in the world for which it is necessary other investigations that focus on the Mexican population, in this case potosine. The objective of this study is to describe the clinical and respiratory characteristics of seriously ill and deceased patients with COVID-19, in a state in northeastern Mexico. And determine comorbidities, in order to apply better measures aimed at safeguarding the population at risk. Design: prospective and observational in the same medical center. Methods: Different types of variables, such as demographic data, severity, laboratory variables, ventilatory assistance received (high-flow oxygen therapy [HFO] and invasive mechanical ventilation [IMV]), oxygenation $\left(\mathrm{PaO}_{2}, \mathrm{PaO}_{2} / \mathrm{FiO}_{2}\right)$, comorbidities and complications were automatically obtained. In order to analyze the difference between medians, the Fisher test (categorical variables) and the Mann-Whitney $U$ test were used. A value of $\mathrm{p}<0.001$ was considered significant. Results: 163 patients were included ( $\mathrm{G} 1=51[31.2 \%]$; G2 $=92[56.44 \%]$ and $\mathrm{G} 3=20[31.74 \%])$; age 65 (52-72) years; $68 \%$ men, APACHE II 18 (15 - 24); SOFA 6 (4-7); arterial hypertension $(25.11 \%)$ and obesity $(16.82 \%)$ were the most frequent comorbidities. HFO was used in $62.7 \%$ of the patients, $85 \%$ failed. $95 \%$ of the patients required IMV and $85 \%$ ventilation in the prone position. In the population, baseline $\mathrm{PaO}_{2} / \mathrm{FiO}_{2}$ improved at the 7th day (165 [125-210] vs 194 [153-285]; $\left.\mathrm{p}=0.02\right)$, as in $\mathrm{G} 1$ (164 [125-197] vs 207 [160-294]; $p=0.07)$, but not in G2 (163 [95-197] vs. 135 [85-177]). The development of pneumonia associated with IMV was high. The amount of D-dimer and IL-6 was also significantly increased in patients who died on the 7th day of the study. Conclusions: The lack of improvement in $\mathrm{PaO}_{2} / \mathrm{FiO}_{2}$ at the 7th day could be a prognostic marker for deterioration, as well as D-dimer and IL-6 secretion. Special attention needs to be paid to managing hypertension and diabetes in adults over 60 years of age. Which was the age group with the highest mortality.
\end{abstract}

\section{Introduction}

On March 11, 2020, the World Health Organization (WHO) declares a new pandemic due to the rapid spread of SARS-CoV-2 outside of China [1]. Patients infected with SARS-CoV-2 can develop a severe viral pneumonia named COVID-19 disease, characterized by severe respiratory failure that leads to a high demand for beds in intensive care units (ICU), putting the national health system to the test $[2,3]$. On February 27, 2020, the first case of COVID-19 was diagnosed in Mexico [4], and almost a month later on March 13, 2020, the first case was diagnosed in San Luis Potosi.

San Luis Potosi is one of the thirty-one states that, together with Mexico City, make up Mexico. It is located in the central Mexican highlands. The total area of the state is $60,546.79 \mathrm{~km}^{2}$ and represents approximately three percent of the total area of the country. It is divided into 58 municipalities. The admission of COVID-19 patients to ICUs varies markedly between countries, from $9 \%$ in Italy [4] to $32 \%$ in China [5]. According to data published by the National Epidemiological Surveillance System [6] dated January 31, 2021, of the 24448 hospitalized patients, 291were admitted to the ICU, which corresponds to $1.19 \%$ of admissions within the ICU, with a total of $158,536,000$ deaths, of which 32,729 occurred only in January 2021. Taking into consideration that both the characteristics of the patients admitted to the ICU for COVID-19, as well as the 
care received and therefore the raw mortality, may vary substantially between medical centers [7] and countries [3,5,710]. The high rates of hypertension, obesity and diabetes in San Luis Potosí are worrying, since it has been shown that the existence of comorbidities associated with SARS-CoV-2 infection increases the risk of mortality, however most of the evidence comes from of other populations in the world for which it is necessary other investigations that focus on the Mexican population, in this case potosine. Our objective is to describe the clinical and respiratory characteristics of a series of consecutive cases of patients with severe COVID-19 disease in a third level hospital, differentiating the patients according to their evolution in the ICU at 28 days and determined comorbidities, in order to apply better measures aimed at safeguarding the population at risk.

\section{Material and methods}

Prospective and observational cohort study, which includes all patients admitted consecutively to the intensive care unit from March 14 to January 31, 2021, with a confirmed diagnosis of SARS-CoV-2 infection, through sample analysis obtained by nasopharyngeal swab and/or bronchial aspiration using RT-PCR, according to the criteria established by the World Health Organization [11].

The study was approved by the Ethics and Research Committee (203301410A0074). Informed consent for the secondary use of the data obtained automatically was requested verbally from the patients or their direct relatives, recording it in the electronic medical record. The present study was carried out with data stored in the database of the clinical information system (CIS) of our center. Data have been routinely stored through the CIS through manual records, automatic capture through devices, and automatic integration with the laboratory and the Hospital Information System of our center. Depending on the source and type, data are stored in different tables within the CIS database. Each table has at least one field or attribute that relates it to another table within the system (relational schema), allowing the integration of all data. The cohort was integrated from the raw tables of the CIS database and has been fully implemented using free software (Python 3.0, Jupyter Notebook).

\section{Variables}

Different types of variables were obtained during the study, such as demographic data, severity (APACHE II), level of organ dysfunction at admission (SOFA score) and comorbidities; as well as, clinical variables (mean arterial pressure $[\mathrm{MAP}]$, heart rate $[\mathrm{HR}]$ and respiratory rate $[\mathrm{RF}]$ ), and variables related to ventilatory assistance and oxygenation (need for invasive mechanical ventilation [IMV], high-flow oxygen therapy [HFO], arterial oxygen pressure $\left[\mathrm{PaO}_{2}\right]$, arterial carbon dioxide pressure $\left[\mathrm{PaCO}_{2}\right]$, inspired fraction of oxygen $\left[\mathrm{FiO}_{2}\right]$, arterial $\mathrm{pH}, \mathrm{PaO}_{2} / \mathrm{FiO}_{2}$ ratio, peak pressure [Pmax], plateau pressure [PPl], positive pressure at the end of expiration [PEEP]). In addition, laboratory variables such as hemoglobin levels, leukocytes, lactate, C-reactive protein (CRP) and procalcitonin (PCT) were considered. All variables were obtained at admission and at the 7th, 14th and 28th days of evolution in order to make comparisons.

Indication for orotracheal intubation (OTI), HFO or mechanical ventilation (MV) was made by the doctor in charge of the patient; there was no specific protocol for respiratory management for COVID-19. Due to the suggestion of not using non-invasive ventilation (NIV) or HFO due to the generation of aerosols [12], the use of NIV was inadvisable based on internal consensus, while the use of HFO was indicated in the context of the limited availability of respirators or as strategy to delay or avoid MV. All patients who failed HFO were intubated and subsequently received MV. No patient was considered with limitation of life support treatment. Assessment of the admission of patients to the ICU was carried out in accordance with the corresponding ethical recommendations [13].

The patients were differentiated according to their evolution at 28 days into three groups: survivors (Group 1); deceased (Group 2) and finally, those who were still in the ICU at 28 days (Group 3).

\section{Statistical analysis}

Due to the characteristics of the study, sample size was not calculated, so this was equal to the number of seriously ill patients admitted during the study period. Continuous variables are presented as median and interquartile ranges (IQR); categorical variables are expressed as number of cases and their percentages. The difference in the distribution of the variables considered between the groups of patients was studied using the Chi-square test or Fisher's exact test (categorical variables). Differences between medians were determined using the Wilcoxon test or the Mann-Whitney U test (non-parametric). Given the limited number of cases, no multivariate analyzes were performed for comparisons. A p $<0.05$ was considered significant. The analysis was carried out using the GraphPad Prism (version 9.01) statistical package.

\section{Results}

\section{General characteristics}

In an area of $60,546.79 \mathrm{~km}^{2}$ and in 58 municipalities the number of positive cases for SARS CoV-2 is shown, where it can be observed that in San Luis Potosi there is a greater number of cases compared to other municipalities (Figure 1). From the beginning of the pandemic in Mexico until January 31, 2021, 652 cases of COVID-19 were diagnosed, where 163 of them (25\%) required admission to the ICU due to the presence of acute respiratory failure and are the reason for this analysis [14-19] (Figure 2A). Of this number, 86.78\% required outpatient care and only $13.22 \%$ were hospitalized (Figure $2 \mathrm{~B}$ ). Of which $51.71 \%$ were men and $48.29 \%$ were women. (Figure 2C). Two hundred and sixty (40\%) were admitted from the internal medicine service, $98(15 \%)$ were referred to other hospitals, and 131 (20\%) were from the emergency department of our hospital. Although the patients received conventional oxygen therapy and some occasions HFO before admission to our ICU, these data are not available for analysis. The median time from hospital admission to ICU was only one day (0.03.0).

The baseline characteristics of the patients are shown in Table 1. The median days to death was 23 (IQR: 11-40) days. The mean stay in the ICU for patients in group 1 was 27 days (IQR: 13-34). In general the patients were between 60-75 years of age (Figure 3), predominantly male, with a high level of severity, as expressed by the median values of APACHE (18) and SOFA (6). A significant increase $(p=0.02)$ in mortality 
Table 1. Characteristics of the 163 critically ill patients who presented COVID 19 in the ICU

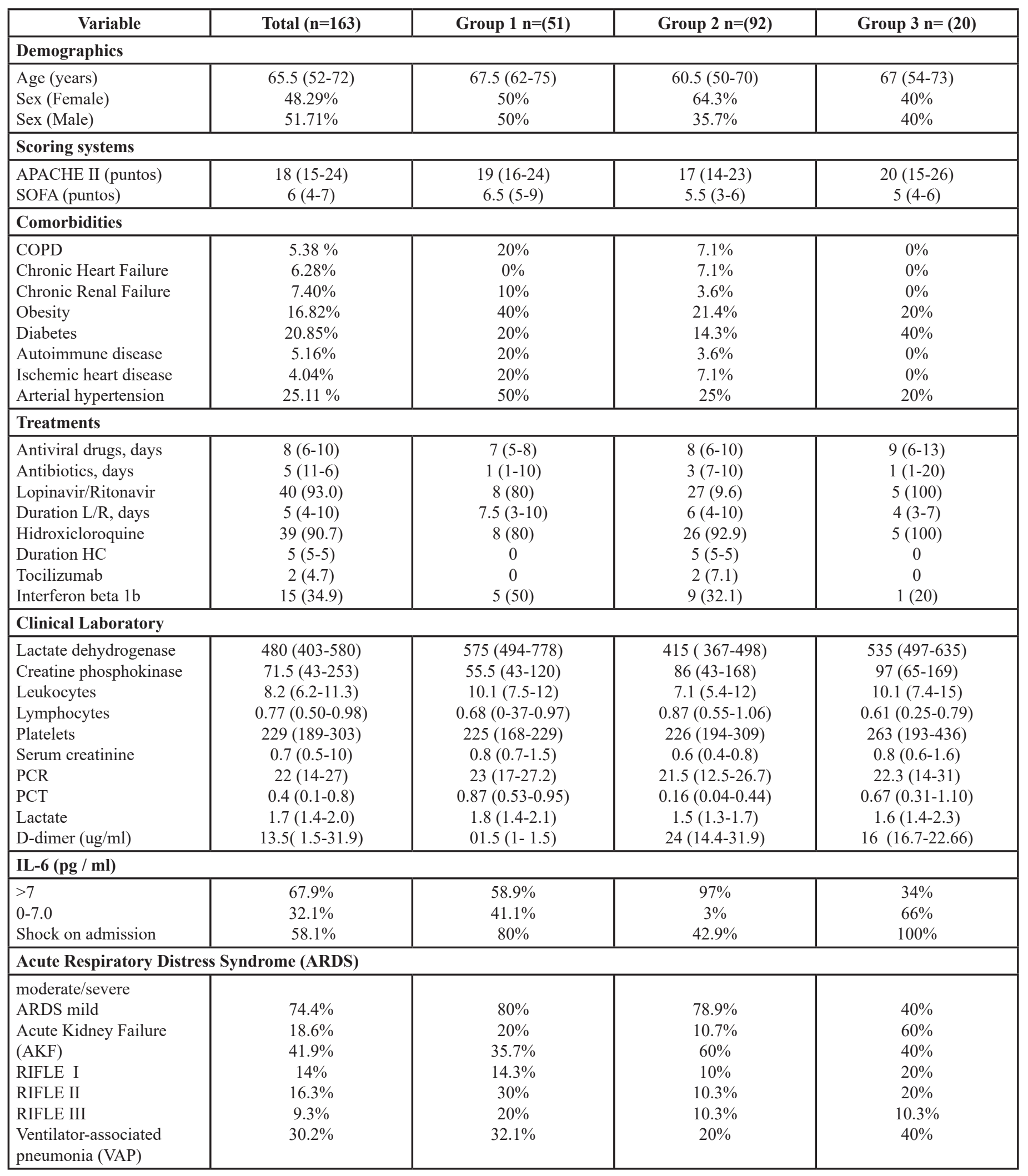

Data are median (IQR), n (\%), or n/N (\%). P -values were calculated using the Mann-Whitney U test, x2 test, or Fisher exact test. 


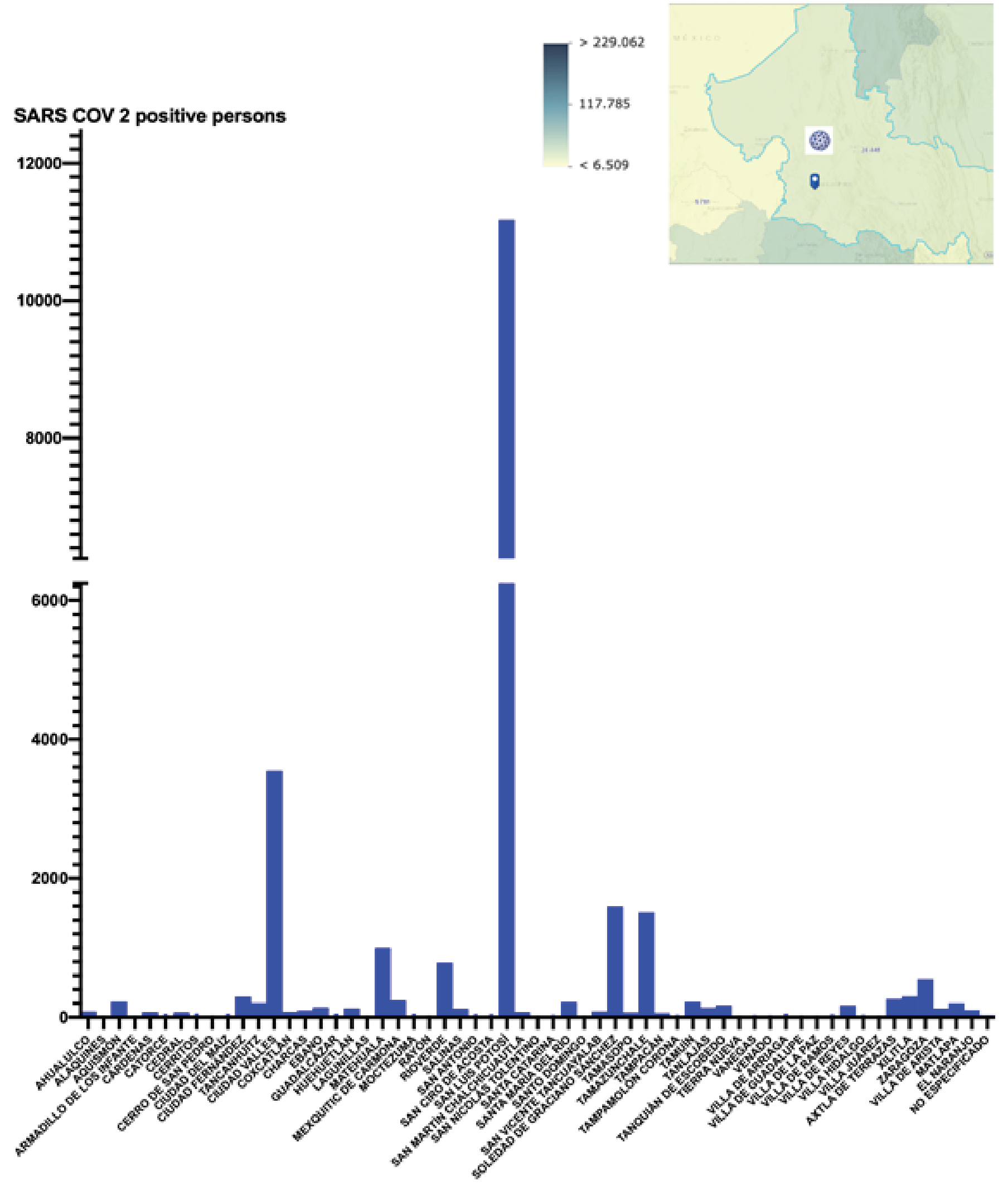

Figure 1. Area of 60,546.79 $\mathrm{km}^{2}$ of the state of San Luis Potosi, and the number of people positive for SARS CoV-2 by municipality. 


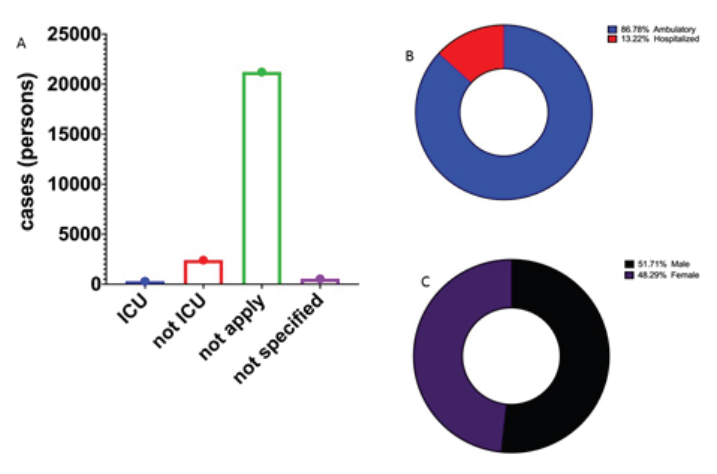

Figure 2. From the beginning of the pandemic in Mexico until January 31, 2021, 652 cases of COVID-19 were diagnosed. A) $25 \%$, required admission to the ICU B) Of this number, $86.78 \%$ required outpatient care and only $13.22 \%$ were hospitalized.

C) Of which $51.71 \%$ were men and $48.29 \%$ were women.

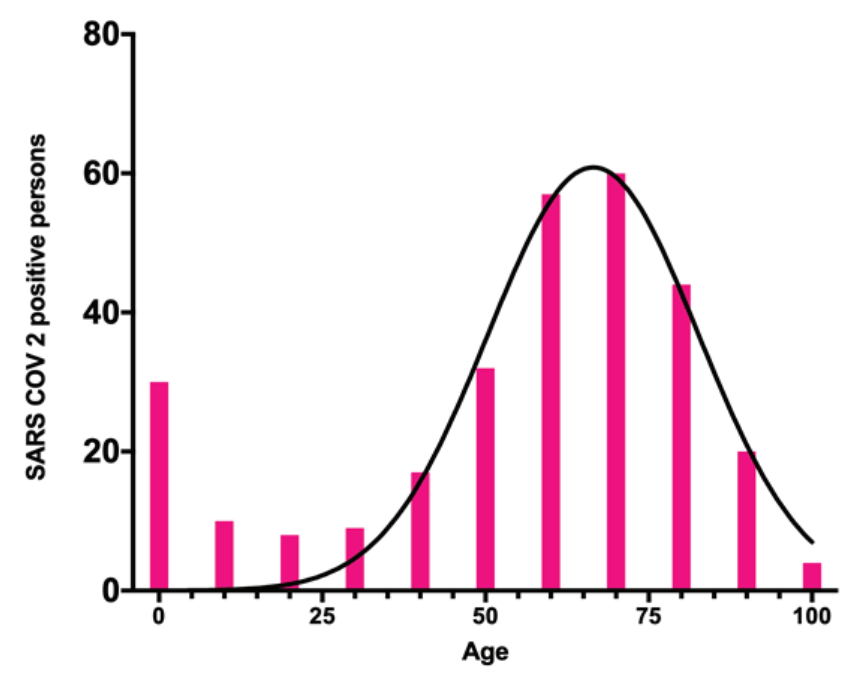

Figure 3. Frequency distribution by age of people positive for SARS CoV - 2 in the state of San Luis Potosi. Where the predominant age between $60-75$ years is observed..

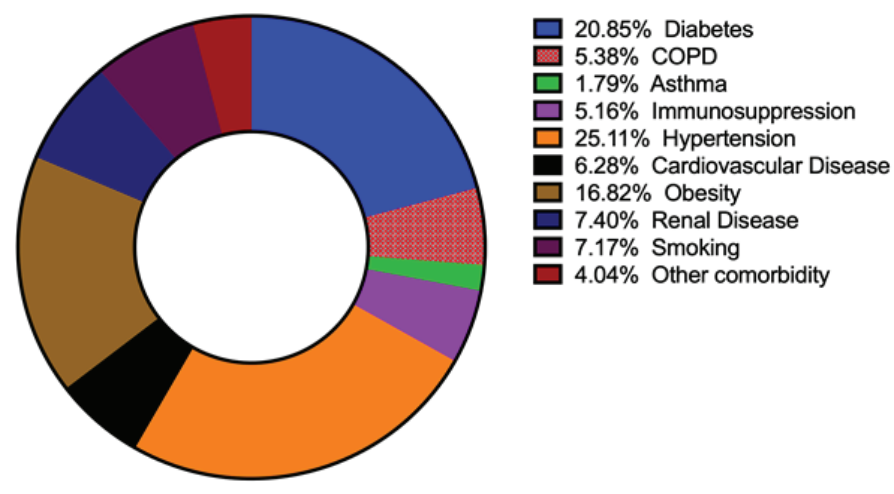

Figure 4. Frequency distribution of comorbidities present in Potosinos admitted to a tertiary hospital. Highlighting hypertension, followed by diabetes.

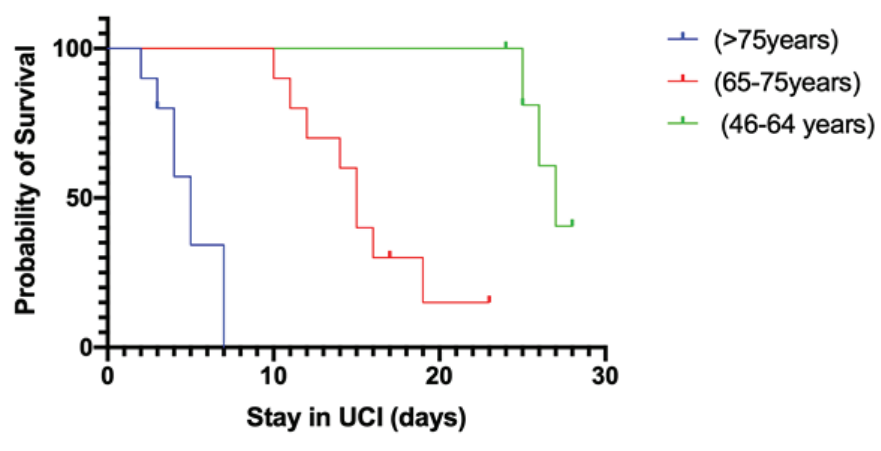

Figure 5. Survival distributions for the different age cutoff levels established for the patients included. Mortality in patients older than 75 years was early, during the first week. $*_{p}<0.0001$.
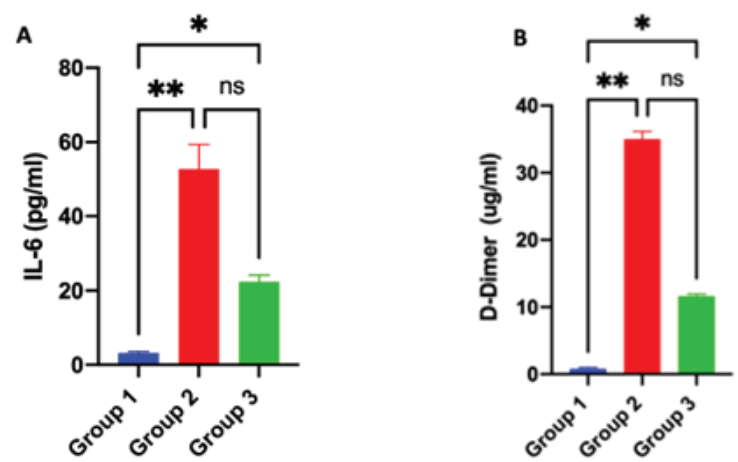

Figure 6. Serum levels of Il-6 and D-dimer in patients with COVID-19. *,**p<0.0001 
Table 2. Variables related to oxygenation of the 163 critically ill patients who presented COVID 19 in ICU

\begin{tabular}{|c|c|c|c|c|}
\hline Variables & Total $(n=163)$ & Group $1 \mathrm{n}=(51)$ & Group 2 n=(92) & Group $3 n=(20)$ \\
\hline \multicolumn{5}{|c|}{ Variables at admission } \\
\hline $\mathrm{PaO}_{2}(\mathrm{mmHg})$ & $100(80-125)$ & $110(74-130)$ & $99(79.8-123)$ & $99(89-117)$ \\
\hline $\mathrm{FiO}_{2}(\%)$ & $60(50-80)$ & $70(60-80)$ & $57(50-80)$ & $60(45-62)$ \\
\hline $\mathrm{PaO}_{2} / \mathrm{FiO}_{2}$ & $165(125-210)$ & $163(95-197)$ & $164(125-197)$ & $210(149-224)$ \\
\hline $\mathrm{PaCO}_{2}(\mathrm{mmHg})$ & $43(38-49)$ & $47(40-52)$ & $41(35-44)$ & $52(40-53)$ \\
\hline pHa & $7.38(7.34-7.43)$ & $7.35(7.33-7.38)$ & $7.41(7.38-7.44)$ & $7.34(7.28-7.39)$ \\
\hline \multicolumn{5}{|c|}{ Variables after 7 days of admission } \\
\hline $\mathrm{PaO}_{2}(\mathrm{mmHg})$ & $102(80-124)$ & $83(69-104)$ & $105(83-126)$ & $121(101-173)$ \\
\hline $\mathrm{FiO}_{2}(\%)$ & $50(40-60)$ & $62(52-80)$ & $50(40-55)$ & $50(40-72)$ \\
\hline $\mathrm{PaO}_{2} / \mathrm{FiO}_{2}$ & 194 (153-285) & $135(85-177)$ & $207(160-294)$ & $251(181-373)$ \\
\hline $\mathrm{PaCO}_{2}(\mathrm{mmHg})$ & $44(42-56)$ & $61(58-75)$ & $43(41-49)$ & $45(43-49)$ \\
\hline $\mathrm{pHa}$ & $7.43(7.36-7.46)$ & $7.29(7.25-7.35)$ & $7.43(7.41-7.47)$ & $7.44(7.43-7.52)$ \\
\hline \multicolumn{5}{|c|}{ Variables after 14 days of admission } \\
\hline $\mathrm{PaO}_{2}(\mathrm{mmHg})$ & $100(85-123)$ & $100(85-123)$ & $79(79.8-123)$ & $100(88-110)$ \\
\hline $\mathrm{FiO}_{2}(\%)$ & $50(40-60)$ & $50(40-60)$ & $46(50-80)$ & $50(40-60)$ \\
\hline $\mathrm{PaO}_{2} / \mathrm{FiO}_{2}$ & $184(163-235)$ & $124(133-205)$ & $120(125-197)$ & $124(120-180)$ \\
\hline $\mathrm{PaCO}_{2}(\mathrm{mmHg})$ & $42(42-56)$ & $45(47-56)$ & $37(35-44)$ & $45(45-50)$ \\
\hline $\mathrm{pHa}$ & $7.44(7.2-7.46)$ & $7.44(7.2-7.46)$ & $7.4(7.38-7.44)$ & $7.4(7.2-7.46)$ \\
\hline \multicolumn{5}{|c|}{ Variables after 28 days of admission } \\
\hline $\mathrm{PaO}_{2}(\mathrm{mmHg})$ & $100(75-100)$ & $100(80-124)$ & NR & $100(85-125)$ \\
\hline $\mathrm{FiO}_{2}(\%)$ & $50(50-80)$ & $50(40-60)$ & $\mathrm{NR}$ & $60(40-70)$ \\
\hline $\mathrm{PaO}_{2} / \mathrm{FiO}_{2}$ & $172(150-200)$ & $135(100-285)$ & NR & $165(133-205)$ \\
\hline $\mathrm{PaCO}_{2}(\mathrm{mmHg})$ & $43(38-42)$ & $44(42-56)$ & $\mathrm{NR}$ & $45(47-56)$ \\
\hline $\mathrm{pHa}$ & $7.40(7.35-7.45)$ & $7.43(7.36-7.46)$ & NR & $7.4(7.2-7.46)$ \\
\hline
\end{tabular}

$\mathrm{FiO}_{2}$, Inspired oxygen fraction; $\mathrm{PaCO}_{2}$, Partial pressure of arterial carbon dioxide; $\mathrm{PaO}_{2}$, partial pressure of arterial oxygen. All comparisons considering group 1 as a reference. ${ }^{* *} \mathrm{p}<0.0001$ Data are medians with their interquartile range. NR:No Record.

was observed according to the established age categories: 18 to 45 years $(0 \%)$; $46-64$ years $(13.0 \%), 65-75$ years $(30.3 \%)$ and older than 75 years $(66.7 \%)$. Mortality in patients older than 75 years was early, during the first week (Figure. 5). Two health workers from our hospital were admitted to the ICU affected by COVID-19, losing their lives. The main comorbidities were hypertension $(25.11 \%)$, diabetes $(20.85 \%)$, obesity (16.82\%), cardiovascular disease (6.28\%), chronic obstructive pulmonary disease (COPD: 5.3\%), followed by immunosuppression (5.16\%, Figure 4). Among the patients with hypertension, $53.8 \%$ had a history of medication related to angiotensin converting enzyme inhibitors (ACEIs) or angiotensin receptor antagonists (ARAs). Only the presence of shock during the admission was more frequent in deceased patients (80\%) compared to the surviving group (group $1=$ 42.9\%; Table 1). The other variables considered did not have statistically significant differences between the groups, with exception of the lack of improvement in $\mathrm{PaO} 2 / \mathrm{FiO} 2$ at the 7 th day and D-dimer and IL-6 secretion. The levels of IL- 6 and D-dimer increased $67.9 \%$ and $15 \%$ compared patient group 1 vs group 2 and 3 (Figure 6).

\section{Treatment}

The time from the onset of symptoms to the first antiviral dose was prolonged, with a median of eight days (IQR: 6-10), with no differences between the groups. Lopinavir/ritonavir were administered in $40(93 \%)$ patients, with a median duration of only five days (IQR: 3.5-10) due to complications related to the marked elevation of transaminases, which conditioned the withdrawal of treatment. Hydroxychloroquine was administered to 39 (90.7\%) patients with a median duration of five days. Interferon $ß-1 b$ was only administered in 15 patients $(34.9 \%)$ due to drug availability problems and only two patients $(4.7 \%)$ received tocilizumab in other medical centers, before their referral to our ICU (Table 1). The administration of corticosteroids was not considered within the treatment for COVID-19. It was administered on admission to the ICU in only one $(2.3 \%)$ patient in order to continue his chronic treatment. Five patients (11.6\%) received methylprednisolone as survival treatment for persistent pulmonary infiltrates after the second week of stay, and four patients (9.3\%) received the medication for other causes such as thrombocytopenia $(n=1)$, hemolytic anemia $(n=1)$ and skin rash $(n=2)$. 


\section{Ventilatory assistance}

All patients required some type of ventilatory assistance during the first hours of admission to the ICU. HFO was used as the initial treatment for respiratory failure due to COVID-19 in 27 patients (62.7\%); however, at $24 \mathrm{~h}$ only four patients responded favorably, which is equivalent to a failure rate of $85.2 \%(4 / 27)$. On day 7 , only two patients maintained HFO and they were discharged as survivors, without requiring any other type of respiratory support. The median time to HFO failure was $8 \mathrm{~h}$ (IQR: 6-20 h). All patients who failed were subsequently intubated and ventilated. IMV was used as the first treatment option for acute respiratory failure in 16 patients (37.2\%); however, during the first 24 hours, 37 (86\%) of the 43 patients were ventilated and finally, at 7 days, 41 (95\%) required IMV. Of the patients on IMV, $34(82 \%)$ required at least one episode of prone ventilation, with a median of three (1-5) maneuvers per patient; although some received more than 10 periods of prone ventilation. Only one patient $(2.3 \%)$ was transported to the referral hospital for ECMO, who finally died. The median days of IMV was 27 (IQR: 15-38), which was similar in both survivors (23 days [IQR: 12-30]) and deceased (27 days [IQR: $13-38 ; \mathrm{p}=0.37$ ]. Of the 37 patients who required IMV, 32 (86.5\%) completed their evolution in the ICU at the time of analysis, with a raw mortality of $28.1 \%$ (9/32), similar to those patients who did not require IMV during the first 24 $\mathrm{h}(16.6 \% ; \mathrm{p}=0.55) .93 \%(40 / 43)$ of the patients met the criteria for ARDS, where $32(74.4 \%)$ were moderate/severe and eight (18.6\%) were mild. Of the 32 patients with moderate/severe ARDS, 27 (72.9\%) received IMV at $24 \mathrm{~h}$, but four (14.8\%) were maintained with HFO, and one patient with a face mask with a reservoir. All the patients with mild ARDS required IMV at 24 h. Regardless of the respiratory support received, the median $\mathrm{PaO}_{2} / \mathrm{FiO}_{2}$ upon admission of the patients was 165 (IQR: 125-210), which increased significantly until day 7 , reaching 194 (153-285; $\mathrm{p}=0.05)$. A similar behavior of $\mathrm{PaO}_{2} / \mathrm{FiO}_{2}$ was observed in the survivors, although without achieving statistical significance $(\mathrm{p}=0.07)$; while in the deceased, the $\mathrm{PaO}_{2} / \mathrm{FiO}_{2}$ was slightly reduced after seven days despite treatment (Table 2).

\section{Discussion}

Our study describes the evolution of 163 seriously ill patients with COVID-19 during the first four weeks in an ICU of a third level hospital. Despite the small number of patients, our results are of great interest, given the lack of knowledge about the evolution of this new disease and the differences in the characteristics of the patients. One of the main findings of our study was that one out of two admitted patients did not show major comorbidities. This finding is similar to those observed in other studies [8-11], which report the presence of comorbidities in more than $60 \%$ of patients. Similar to what was observed during the influenza A (H1N1) pandemic [20], obesity was a very frequent comorbidity in our patients. On the contrary, obesity is not mentioned in the studies carried out in China [9] or Italy [3], but it is mentioned in other center experience [7] and in a recent publication from the US [21] with an even higher level of obese patients (41.7\%). This could make direct extrapolation of international results difficult $[3,8$ $11,20-22]$ when dealing with different populations.
Another relevant finding was that the mortality observed (23.2\%) in our series was lower than the one observed in other study [7] (31\%), despite the similar age and severity of the patients and a similar frequency of IMV (94\%). Different publications also report higher mortality. In the study by Yang $\mathrm{X}$ et al. [9], overall mortality was $61.5 \%$, but when considering patients in IMV, it rose to $81 \%(30 / 37)$, considerably higher than that observed in our study (28.1\%). It should be noted that, in this study, of the 52 critically ill patients, only 22 (42\%) received IMV. Although, the authors do not report the time from failure of other oxygenation techniques to the implementation of IMV, the high mortality of patients in IMV, suggests a significant delay in orotracheal intubation. Additionally, $\mathrm{Wu}$ C et al. [10], report a global mortality of $21.9 \%$. In this study, of the 210 patients included, 165 (78.5\%) received some type of respiratory support, but the low frequency of IMV used (3\%) in patients is also notable, while almost half $(48.8 \%)$ received nasal cannulas and 30\% NIV. Likewise, the study by Grasselli $\mathrm{G}$ et al. [4] carried out in Italy, reported a mortality of $26 \%$. Although this study does not mention severity scales, it seems to include a population more similar to our series, since of the 1,591 patients, $1,287(80 \%)$ were admitted to the ICU, and of these, $89 \%$ required IMV. In addition, the authors associate mortality with age; however, the median age was not different from that of our population (63 vs. 65 years). In New York [21], of the 5,700 patients with COVID-19, only $6.5 \%(n=373)$ were admitted to the ICU and 320 of these $(85.8 \%)$ required IMV. Mortality in this subgroup was very high (88.1\%), similar to the one observed by Arentz M et al. [22] in a small population of 21 patients. The high mortality in this series could be related to a significantly higher median age than in most of the reports (70 years, IQR: 40-92). Contrary to these findings, our mortality was markedly higher than that observed in the study by Guan W et al. [8] of only $1.4 \%$. In this study, the majority of the 1,099 patients were considered non-serious (none required ventilation). Mortality in those considered serious $(15.7 \%$; $173 / 1099)$ was $8.1 \%$, despite the fact that within these patients only $25(2.2 \%)$ received IMV. It is evident that international studies include another type of population and especially another type of ventilatory assistance, which makes it very difficult to transfer this experience to our environment; therefore, their data must be carefully interpreted.

Another interesting finding was to observe that, despite the recommendations against its use [12], HFO was applied in more than $60 \%$ of the patients as the first line of treatment. However, failure was observed in more than $85 \%$ of the cases. Although with the available data, we cannot evaluate the impact of the intubation delay in relation to the evolution; it is possible that a gap of $8 \mathrm{~h}$ from the HFO failure to the intubation, has not significantly affected the evolution, considering the observed mortality.

A worrying fact was to observe a high rate of NAV $(30 \%$ or 13 cases/1,000 days of IMV), which widely duplicates the usual rate in our ICU. This frequency is higher than the one reported by Xang X et al. [9] (13.5\%); although, the authors do not indicate days of risk exposure, which is why it is difficult to make comparisons. Work urgency during the pandemic, the use of personal protective equipment, the rotation of poorly trained personnel, as well as a decrease in NAV prevention measures, may be the reasons that justify this increase. 
However, this high incidence must be confirmed with other studies.

Finally, our data show that in deceased patients, the $\mathrm{PaO}_{2} /$ $\mathrm{FiO}_{2}$ at admission did not improve after seven days despite treatment. In survivors, $\mathrm{PaO}_{2} / \mathrm{FiO}_{2}$ increased at seven days; therefore, we can hypothesize that the lack of improvement in $\mathrm{PaO}_{2} / \mathrm{FiO}_{2}$ at one week of treatment could be a prognostic factor to be considered in new studies. It is evident that our study has important limitations that should be highlighted. The first limitation and possibly the most important, is the low number of patients included. Because of this, it is possible that differences between groups cannot be evidenced due to a type I error; however, given the novel characteristics of this pandemic, our data add value to knowledge, although the findings must be confirmed by studies with a larger number of patients. Second, our results describe the evolution in a special type of ICU and cannot possibly be generalized to other areas or other ICUs. It is evident that both the indication for ICU admission, as well as the complexity of the care provided to patients, is highly variable between medical centers and countries; therefore, this information must be carefully analyzed in each study.

In conclusion, our data suggest that despite describing the evolution of a population with little advanced age and with a low level of comorbidities, COVID-19 requires a high frequency of IMV due to ARDS, has a high incidence of HFO failure and high mortality. The lack of improvement in $\mathrm{PaO}_{2} /$ $\mathrm{FiO}_{2}$ after one week of active treatment could be considered as a variable associated with early mortality, as well as D-dimer and IL- 6 secretion; although these data should be confirmed in future studies.

\section{Conflict of interest}

The authors declare that they do not have any conflicts of interest.

\section{Funding}

This study is funded by CEEPAC San Luis Potosi.

\section{References}

1. World Health Organization.Novel coronavirus (2019-nCov) situation report-1.2020. https://www.who.int/docs/defaultsource/coronaviruse/situations-reports.

2. Ferrer R. Pandemia por Covid-19: el mayor reto dela historia del intensivismo. Med Intensiva. 2020.

3. Suarez V, Suarez-Quezada M, Oros-Ruiz S, Ronquillo de Jesus E. Epidemiología de COVID 19 en México: del 17 de febrero al 20 de abril del 2020.Rev. Clinica Española. 2020;20:463-471.

4. Grasselli G, Zangrillo A, Zanella A, et al. Baseline Characteristics and Outcomes of 1591 Patients Infected With SARS-CoV-2 Admitted to ICUs of the Lombardy Region, Italy. JAMA. 2020;323(16):1574-1581.

5. Huang C, Wang Y, Li X, et al. Clinical features of patients infected with 2019 novel coronavirus in Wuhan China. Lancet. 2020;395:497-506.

6. Secretaría de Salud. Lineamiento estandarizado para la vigilancia epidemiológica y por laboratorio d ela enfermedad respiratoria viral. 2020

7. Salinas Aguirre JE, Sánchez García C, Rodríguez Sanchez R, Rodríguez Muñoz L, Díaz Castaño A, Bernal Gómez R. Características clínicas y comorbilidades asociadas a mortalidad en pacientes con COVID 19 en Coahuila, México. Rev Clin Esp. 2021; Epub ahead of print.

8. Guan W, Ni Z, Hu Y, et al. Clinical Characteristics of Coronavirus Disease 2019 in China. N Eng J Med. 2020 [Online ahead of print]

9. Yang $\mathrm{X}, \mathrm{Yu} \mathrm{Y,Xu} \mathrm{J,} \mathrm{et} \mathrm{al.} \mathrm{Clinical} \mathrm{course} \mathrm{and} \mathrm{outcomes} \mathrm{of}$ critically ill patients with SARS-CoV-2 pneumonia in Wuhan China: a single-centered, retrospective, observational study. Lancet Respir Med. 2020;8(5): P475-481

10. Wu C, Chen X, Cai Y, et al. Risk Factors Associated With Acute Respiratory Distress Syndrome and Death in Patients With Coronavirus Disease 2019 Pneumonia in Wuhan, China. JAMA Intern Med. 2020;180(7):934-943.

11. World Health Organization (WHO). Laboratory testing for 2019 novel coronavirus (2019-nCoV) in suspected human cases [consultado 14 Enero 2021].

12. Ministerio de Sanidad. Documento técnico. Manejo clínico del COVID-19. Unidades de Cuidados Intensivos.

13. Rubio O, Estella A, Cabre L, et al. Recomendaciones éticas para la toma de decisiones difíciles en las unidades de cuidados intensivos ante la situación excepcional de crisis por la pandemia por COVID-19: revisión rápida y consenso de expertos [Ethical recommendations for a difficult decision-making in intensive care units due to the exceptional situation of crisis by the COVID-19 pandemia: A rapid review \& consensus of experts]. Med Intensiva. 2020;44(7):439-445.

14. Parra-Bracamonte GM, Lopez-Villalobos N, Parra-Bracamontes FE. Clinical characteristics and risk factors for mortality of patients with COVID -19 in a large data set form Mexico. Ann Epidemiolo.2020; 5293-98.

15. Martin-Loeches I, Schultz MJ, Vincent JL, et al. Increased incidence of co-infection in critically ill patients with influenza. Intensive Care Med. 2017;43:48-58.

16. Kalil AC, Metersky ML, Klompas M, et al. Management of adults with hospital-acquired and ventilator- associated pneumonia: 2016 clinical practice guidelines by the Infectious Diseases Society of America and the American Thoracic Society. Clin Infect Dis. 2016;63: e61-111.

17. Ranieri VM, Rubenfeld GD, Thompson BT, et al. Acute respiratory distress syndrome: the Berlin Definition. ARDS Definition Task Force. JAMA. 2012;307:2526-33.

18. Bellomo R, Ronco C, Kellum JA, Mehta RL, Palevsky P. the ADQI workgroup Acute renal failure - definition, outcome measures, animal models, fluid therapy and information technology needs: The Second International Consensus Conference of the Acute Dialysis Quality Initiative (ADQI) Group. Crit Care. 2004;8:R204-12.

19. Moreno G, Rodríguez A, Reyes LF, et al. Corticosteroid treatment in critically ill patients with severe influenza pneumonia: A propensity score matching study. Intensive Care Med. 2018;44:1470-82.

20. Díaz E, Rodríguez A, Martin-Loeches I, Lorente L, et al. Impact of obesity in patients infected with 2009 influenza A (H1N1). Chest. 2011;139:382-6.

21. Richardson S, Hirsch JS, Narasimhan M, et al. Presenting Characteristics, Comorbidities, and Outcomes Among 5700 Patients Hospitalized With COVID-19 in the New York City Area. JAMA. 2020;323(20):2052-2059.

22. Arentz M, Yim E, Klaff L, et al. Characteristics and Outcomes of 21 Critically Ill Patients With COVID-19 in Washington State. JAMA. 2020;323(16):1612-1614. 